\title{
Annealing twins in a multifunctional beta Ti-Nb-Ta-Zr-O alloy
}

\author{
W Y GUO* and $\mathrm{J} \mathrm{SUN}^{\dagger}$ \\ Shanghai Baosteel Packaging Co. Ltd, Shanghai 201908, P.R. China \\ ${ }^{\dagger}$ School of Materials Science and Engineering, Shanghai Jiao Tong University, Shanghai 200240, P.R. China
}

MS received 10 January 2010; revised 9 February 2011

\begin{abstract}
The grain boundary character distribution and annealing twins in a multifunctional $\beta$-type $\mathrm{Ti}-23 \mathrm{Nb}-0.7 \mathrm{Ta}-2 \mathrm{Zr}-\mathrm{O}$ alloy having a stable $b c c$ phase structure are investigated by electron backscattering diffraction (EBSD). The results show that the coincident site lattice (CSL) boundaries, including $\Sigma 3$ and $\Sigma 11$ twin boundaries mainly form at the early stage of recrystallization. $\{112\}\langle 111\rangle$ and $\{332\}\langle 113\rangle$ annealing twins are observed to occur in the completely recrystallized $\mathrm{Ti}-23 \mathrm{Nb}-0 \cdot 7 \mathrm{Ta}-2 \mathrm{Zr}-\mathrm{O}$ alloy.
\end{abstract}

Keywords. Titanium alloy; annealing; EBSD; CSL; twinning.

\section{Introduction}

Gum metal is a group of recently developed multifunctional $\beta$-type titanium alloys with IVa, Va elements and oxygen, which are basically expressed as $\mathrm{Ti}_{3}(\mathrm{Ta}+$ $\mathrm{Nb}+\mathrm{V})+(\mathrm{Zr}, \mathrm{Hf})+\mathrm{O}$. Those alloys simultaneously match with the following three electronic numbers: (i) a valence electron number $(e / a)$ of about $4 \cdot 24$; (ii) a bond order $(\mathrm{Bo})$ of about 2.87 and (iii) a $d$ electron orbital energy level $(M d)$ of about $2.45 \mathrm{eV}$ (Saito et al 2003a, b; Furuta et al 2005; Hwang et al 2005; Abdel-Hady et al 2006; Gutkin et al 2006; Kuramoto et al 2006a, b). After severe cold swaging, those alloys exhibit many super properties, such as super elasticity, super plasticity, super high strength, ultralow elastic modulus, and Invar and Elinvar properties. These excellent properties are attributed to a unique 'dislocation-free plastic deformation mechanism' (Saito et al 2003a, b).

However, recent research revealed that gum metal actually deforms by traditional dislocation glide on slip systems, rather than by dislocation-free mechanism (Guo et al 2008; Xing et al 2008). Generally, the deformation of crystals proceeds by sliding, twinning and kink. Mechanical twinning often occurs in hexagonal close packed ( $h c p)$ and body centred cubic $(b c c)$ materials such as $\mathrm{Mg}, \alpha-\mathrm{Fe}$, etc. It has been reported that $\{112\}\langle 111\rangle$ and $\{332\}\langle 113\rangle$ twinning take place during plastic deformation in some metastable $\beta$-type titanium alloys having a stable $b c c$ phase structure (Hanada et al 1985; Hanada and Izumi 1986). Very recently, $\{112\}\langle 111\rangle$ mechanical twinning was also observed to occur in a $\beta$-type titanium alloy of which composition is quite close to that of gum

\footnotetext{
*Author for correspondence (guowenyuan2@yahoo.com)
}

metal (Yang et al 2008). Therefore, it is reasonable to consider that the mechanical twinning may also occur in gum metal. Crystallographic misorientation between the matrix and the twin in $\{112\}\langle 111\rangle$ or $\{332\}\langle 113\rangle$ is $70 \cdot 5^{\circ}$ or $50 \cdot 5^{\circ}$ around the $\langle 110\rangle$ axis, which corresponds to $\Sigma 3$ or $\Sigma 11$ coincident site lattice (CSL) boundary (Zhao and Adams 1988), respectively.

Annealing twins are a kind of planar defect frequently observed to form during recrystallization and grain growth in face centred cubic $(f c c)$ materials with low stacking fault energy. However, annealing twins are scarcely observed in $b c c$ materials due to their high stacking fault energy. In this paper, the grain boundary character distribution (GBCD) and annealing twins in severely cold swaged $\mathrm{Ti}-23 \mathrm{Nb}-0 \cdot 7 \mathrm{Ta}-2 \mathrm{Zr}-\mathrm{O}$ alloy during recrystallization were investigated by electron backscattering diffraction (EBSD).

\section{Experimental}

A round rod of gum metal with a typical chemical composition of $\mathrm{Ti}-23 \mathrm{Nb}-0.7 \mathrm{Ta}-2 \mathrm{Zr}-1.2 \mathrm{O}$ (at.\%) alloy with $90 \%$ of substantial cold-swaging was employed as starting material for this study. Optical microstructural examinations revealed a characteristic marble-like structure as earlier indicated by Saito et al (2003a, b). All samples are cross sections of the cold swaged rod, which are perpendicular to the swaging direction. Samples were subjected to a heat treatment in argon atmosphere for 5, $10,15,20,30$ and $120 \mathrm{~min}$ at $820^{\circ} \mathrm{C}$, respectively followed by brine quenching rapidly to obtain partially and completely recrystallized microstructure. The percentage recrystallization is $8 \cdot 4,25 \cdot 2,44,64 \cdot 6,93.7$ and 100 for those samples, respectively and recrystallized grain size is $30-50 \mu \mathrm{m}$ for the completely recrystallized sample 
(Guo et al 2008). X-ray diffractions (XRD) were performed to reveal single $\beta$ phase without $\alpha^{\prime \prime}$ martensite and $\omega$ phase for all samples. Then sections of samples were mechanically ground to $5 \mu \mathrm{m}$ silicon carbide paper finish, and electropolished in a $6 \%$ perchloric acid $+30 \%$ butanol $+64 \%$ methanol solution at a closed circuit voltage of $25 \mathrm{~V}$. The orientation information were collected using a hexagonal grid and a step size of $0.1 \mu \mathrm{m}$ by EDAX EBSD facilities attached to the JEOL JSM-6460 scanning electron microscope operating at $20 \mathrm{kV}$, and then analysed using the orientation imaging microscopy (OIM) software. For generating orientation and grain boundary maps, a grain tolerance angle of $15^{\circ}$ was used, which distinguishes low angle grain boundaries (LAGBs) and high angle grain boundaries (HAGBs). CSL boundaries in all samples were classified according to Brandon's criterion for the maximum permissible deviation $(\Delta \theta)$ from exact coincidence as given by

$$
\Delta \theta \leq 15^{\circ} \Sigma^{-1 / 2} \text {. }
$$

\section{Results and discussion}

Effect of annealing time on GBCD in the cold swaged Ti-23Nb-0.7Ta-2Zr-1.2O alloy is shown in figure 1 . At the early stage of annealing, the frequency decreases sharply for LAGBs, but increases rapidly for random and CSL boundaries. After annealing at $820^{\circ} \mathrm{C}$ for $5 \mathrm{~min}$, the frequency of CSL boundaries reaches a high level, and then increases very slowly with prolonged annealing time. However, the frequency of LAGBs or random boundaries keeps decreasing or increasing respectively till annealing for $15 \mathrm{~min}$, and subsequently changes slightly with prolonged annealing time. When annealing time is $<5 \mathrm{~min}$, nucleation and growth of new grains with different orientations compared to the deformed structure

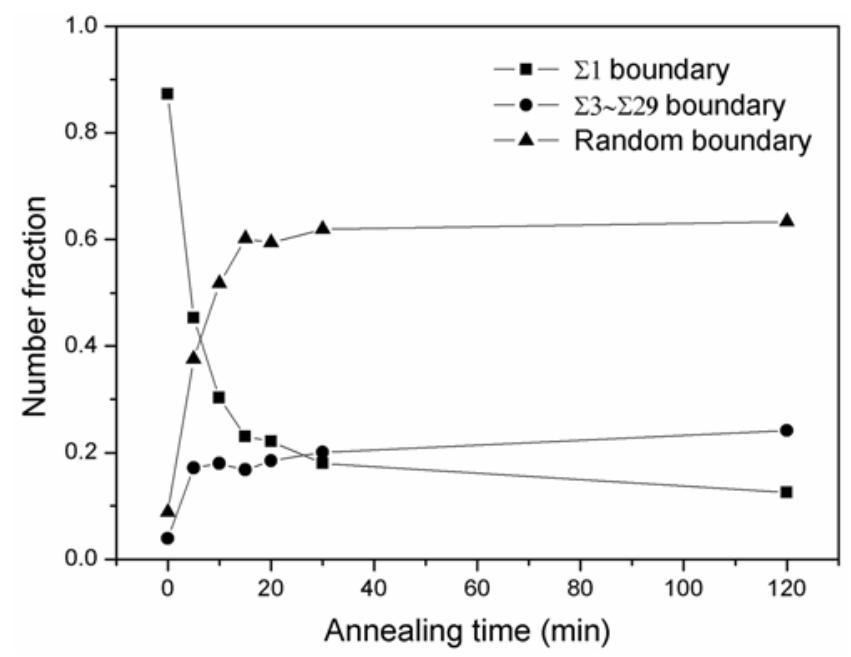

Figure 1. Effect of annealing time on GBCD in cold swaged $\mathrm{Ti}-23 \mathrm{Nb}-0 \cdot 7 \mathrm{Ta}-2 \mathrm{Zr}-1 \cdot 2 \mathrm{O}$ alloy. are proceeding at the site with high deformation stored energy (Guo et al 2008), therefore, it is indicated that CSL boundaries mainly form at the early stage of recrystallization.

The frequency distribution of different CSL boundaries $(\Sigma 3 \sim \Sigma 29)$ in $\mathrm{Ti}-23 \mathrm{Nb}-0.7 \mathrm{Ta}-2 \mathrm{Zr}-1.2 \mathrm{O}$ alloy is shown in figure 2. CSL profiles are different for the alloy annealed at $820^{\circ} \mathrm{C}$ for different times, because heat treatments can alter CSL profiles by allowing the boundary network to move towards equilibrium (Randle 1996). In the severely cold swaged alloy, the frequency of CSL boundaries is very low and $\Sigma 3$ boundary is the main CSL boundary, which indicates that $\{112\}\langle 111\rangle$ deformation twins occur. Mechanical twinning in this alloy has been verified by TEM observation, which will be reported in more detail elsewhere. In the alloy annealed at $820^{\circ} \mathrm{C}$ for different times, the most prominent CSL boundaries are $\Sigma 3$ and $\Sigma 13 \mathrm{~b}$. Meanwhile, a little amount of $\Sigma 11$ boundary is also detected to occur. The $\Sigma 13 b$ boundary between two grains corresponds to a $27.8^{\circ}$ rotation around a $\langle 111\rangle$ axis, which may be related to the preferred orientation in the alloy (Saha and Ray 2007). The occurrence of $\Sigma 3$ and $\Sigma 11$ boundaries indicates that $\{112\}\langle 111\rangle$ and $\{332\}\langle 113\rangle$ annealing twinning may take place.

In the $\mathrm{Ti}-23 \mathrm{Nb}-0 \cdot 7 \mathrm{Ta}-2 \mathrm{Zr}-1.2 \mathrm{O}$ alloy annealed at $820^{\circ} \mathrm{C}$ for $120 \mathrm{~min}$, lamella defects extending across some entire grains are observed, of which appearance is very similar to that of annealing twins, as shown in figures 3(a) and (c). In order to determine whether the lamellar defects are twins, point-to-point and point-to-origin misorientations along the arrows in figures 3(a) and (c) were measured, respectively. The misorientation diagrams are shown in figures 3(b) and (d). The crystallographic misorientations between the matrix and two boundaries of the lamellar defect shown in figure 3(a) are both $50.5^{\circ}$ around the $\langle 110\rangle$ axis, i.e. both boundaries of the lamellar defect are $\Sigma 11$ boundaries, so this lamellar defect should be a $\{332\}\langle 113\rangle$ twin. However, the recrystallized grain containing a lamellar defect shown in figure 3(c) is divided into two parts with different orientations by the lamellar defect, which leads to the crystallographic misorientations of $26^{\circ}$ around the $\langle 210\rangle$ axis and $31^{\circ}$ around the $\langle 320\rangle$ axis between the matrix and the lamellar defect, respectively. For this lamellar defect, the crystallographic misorientations between the matrix and the lamellar defect around the $\langle 110\rangle$ axis can be calculated by the following equation

$$
\tan \frac{\beta}{2}=\tan \frac{\alpha}{2} / \cos \theta
$$

where $\beta$ is the misorientation between the matrix and the lamellar defect around the $\langle 110\rangle$ axis, $\alpha$ the misorientation around the $\langle 210\rangle$ or $\langle 320\rangle$ axis, $\theta$ the angle between $\langle 110\rangle$ and $\langle 210\rangle$ or $\langle 320\rangle$ directions. The crystallographic 

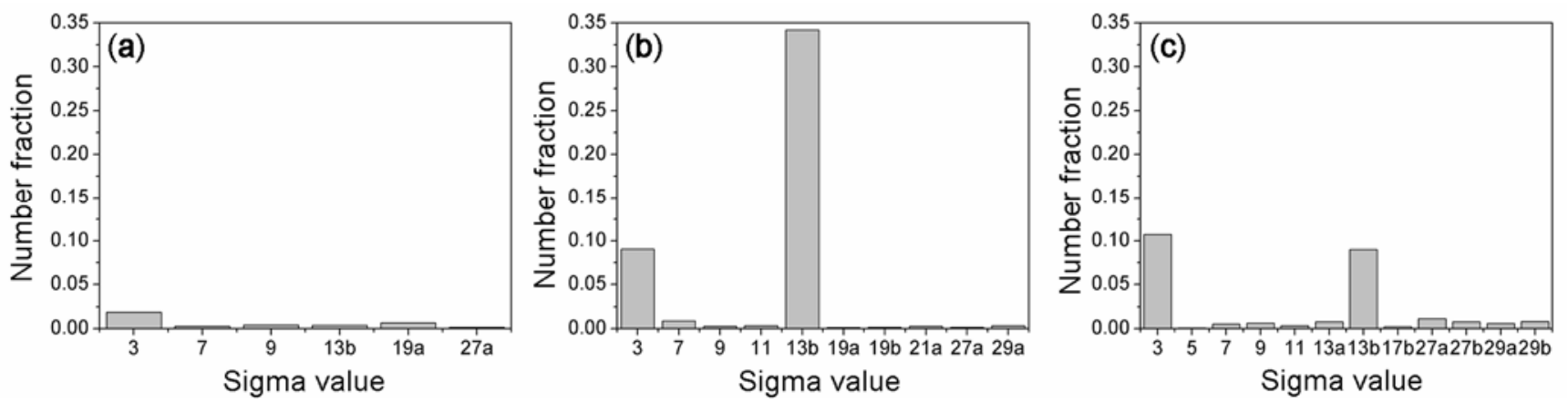

Figure 2. Statistic of CSL boundaries of cold swaged $\mathrm{Ti}-23 \mathrm{Nb}-0 \cdot 7 \mathrm{Ta}-2 \mathrm{Zr}-1 \cdot 2 \mathrm{O}$ alloy after annealing at $820^{\circ} \mathrm{C}$ for $0 \mathrm{~min}(\mathbf{a})$, $5 \mathrm{~min}(\mathbf{b})$ and $120 \mathrm{~min}(\mathbf{c})$.
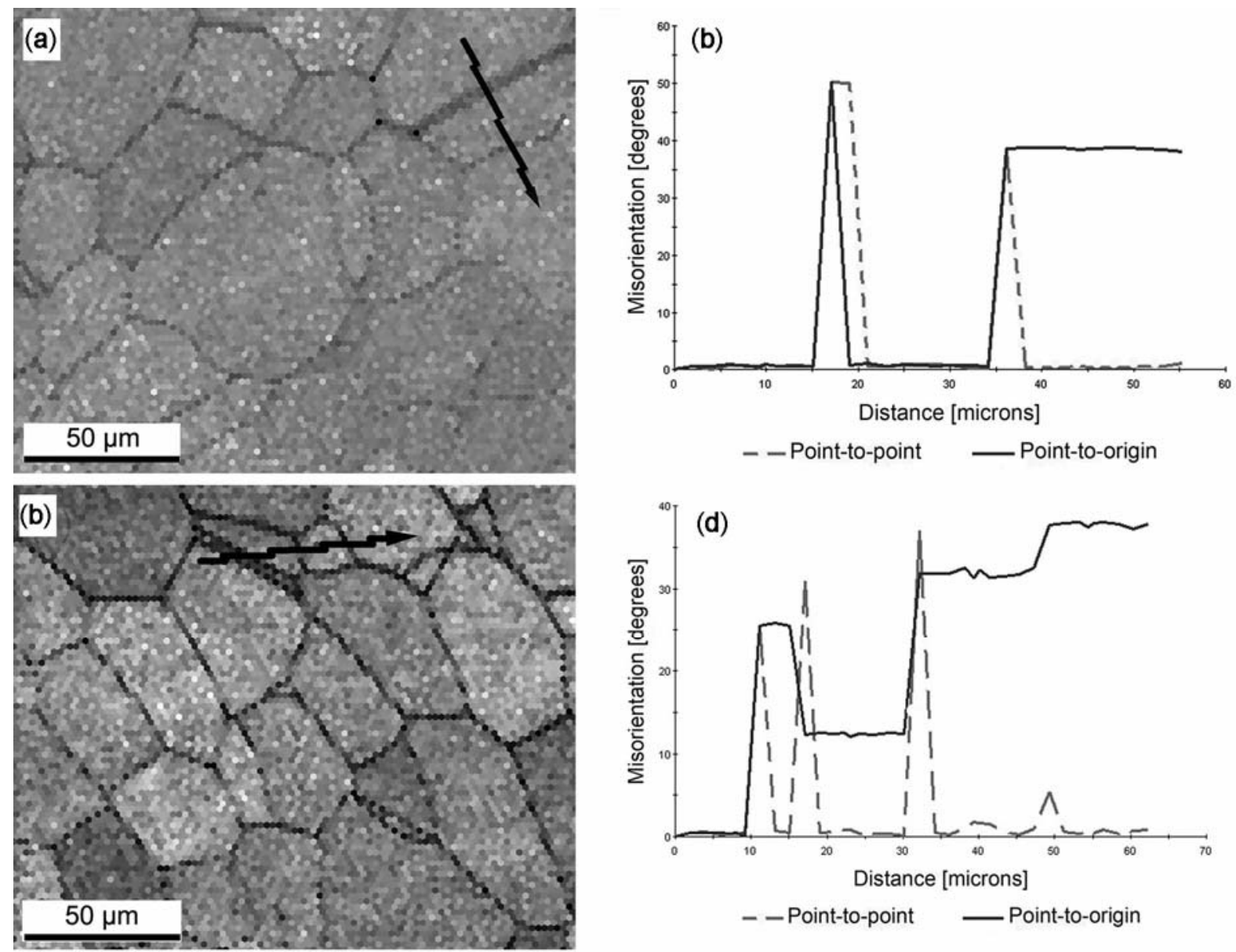

Figure 3. Image quality maps $(\mathbf{a}, \mathbf{c})$ and misorientation diagrams $(\mathbf{b}, \mathbf{d})$ for the $\mathrm{Ti}-23 \mathrm{Nb}-0 \cdot 7 \mathrm{Ta}-2 \mathrm{Zr}-1 \cdot 2 \mathrm{O}$ alloy annealed at $820^{\circ} \mathrm{C}$ for $120 \mathrm{~min}$.

misorientations around the $\langle 110\rangle$ axis between the matrix and the lamellar defect were calculated to be $72.2^{\circ}$ and $70 \cdot 2^{\circ}$, respectively which are very close to $70.5^{\circ}$ of $\{112\}\langle 111\rangle$ twins. According to Brandon's criterion for the maximum permissible deviation, these two boundaries are both $\Sigma 3$ boundaries. Hence it is reasonable to conclude that two boundaries of the lamellar defect is $\{112\}\langle 111\rangle$ twin boundaries, i.e. the lamellar defect is a $\{112\}\langle 111\rangle$ twin.

After annealing at $820^{\circ} \mathrm{C}$ for $30 \mathrm{~min}$, near complete recrystallization has been achieved for Ti-23Nb-0.7Ta$2 \mathrm{Zr}-1 \cdot 2 \mathrm{O}$ alloy (Guo et al 2008), hence grain growth has 
taken place in the sample annealed at $820^{\circ} \mathrm{C}$ for $120 \mathrm{~min}$. Image quality maps in figure 3 show that the recrystallized grains are clean (largely free from defects) and the twins are thin and span opposite sides of the grains. Therefore, these twins must be annealing twins. The low frequency of annealing twins illustrates that twin boundary energy in $\mathrm{Ti}-23 \mathrm{Nb}-0.7 \mathrm{Ta}-$ $2 \mathrm{Zr}-1.2 \mathrm{O}$ alloy is indeed comparable to large angle boundary energy, i.e. the alloy has high stacking fault energy.

Naturally, a low stacking fault energy favours annealing twins. Besides the stacking fault energy, there are many factors which can also influence twin formation in $f c c$ metals, such as the chemical driving force for grain growth and the annealing temperature (Balluffi 1980; Cahn and Haasen 1996). The probability of twin formation increases with both chemical driving force and temperature. Up to now, many hypotheses have been proposed to explain the formation of annealing twins in $f c c$ metals, which can be classified into two different groups: (i) nucleation of twins by stacking faults and (ii) growth accidents (Mahajan et al 1997). However, little work on annealing twins in $b c c$ crystals has been done and the formation mechanism of annealing twins is still not clear. If the foregoing hypotheses are also suitable for $b c c$ crystals, then annealing twins in $\mathrm{Ti}-23 \mathrm{Nb}-0 \cdot 7 \mathrm{Ta}-2 \mathrm{Zr}-1 \cdot 2 \mathrm{O}$ alloy are formed more probably as a consequence of growth accidents during recrystallization than as a consequence of nucleation by stacking faults. The rapid increase of frequency of CSL boundaries indicates that annealing twins mainly form at the early stage of grain growth, and the low frequency of annealing twins in $\mathrm{Ti}-$ $23 \mathrm{Nb}-0 \cdot 7 \mathrm{Ta}-2 \mathrm{Zr}-1 \cdot 2 \mathrm{O}$ alloy means growth accidents are not frequent during grain growth process.

\section{Conclusions}

During recrystallization of $\mathrm{Ti}-23 \mathrm{Nb}-0 \cdot 7 \mathrm{Ta}-2 \mathrm{Zr}-1.2 \mathrm{O}$ alloy, the CSL boundaries mainly form at the early stage.
As the recrystallization proceeds, $\{112\}\langle 111\rangle$ and $\{332\}\langle 113\rangle$ annealing twins occur in the alloy.

\section{Acknowledgements}

The authors would like to acknowledge the financial support from Shanghai Postdoctoral Scientific Program (Grant No. 09R21420300).

\section{References}

Abdel-Hady M, Hinoshita K and Morinaga M 2006 Scr. Mater. 55477

Balluffi R W 1980 Grain boundary structure and kinetics (Metals Park, Ohio: ASM)

Cahn R W and Haasen P 1996 Physical metallurgy (Amsterdam: North Holland) 4th edn

Furuta T, Kuramoto S, Hwang J, Nishino K and Saito T 2005 Mater. Trans., JIM 463001

Guo W Y, Xing H, Sun J, Li X L, Wu J S and Chen R 2008 Metall. Mater. Trans. A39 672

Gutkin M Y, Ishizaki T, Kuramoto S and Ovid'ko I A 2006 Acta Mater. 542489

Hanada S and Izumi O 1986 Metall. Trans. A17 1409

Hanada S, Ozeki M and Izumi O 1985 Metall. Trans. A16 789

Hwang J, Kuramoto S, Furuta T, Nishino K and Saito T 2005 J. Mater. Eng. Perform. 14747

Kuramoto S, Furuta T, Hwang J, Nishino K and Saito T 2006a Metall. Mater. Trans. A37 657

Kuramoto S, Furuta T, Hwang J, Nishino K and Saito T 2006b Mater. Sci. Eng. A442 454

Mahajan S, Pande C S, Imam M A and Rath B B 1997 Acta Mater. 452633

Randle V 1996 The role of the coincidence site lattice in grain boundary engineering (London: Maney Publishing)

Saha R and Ray R K 2007 Scr. Mater. 57841

Saito T et al 2003a Science 300464

Saito T et al 2003b Mater. Sci. Forum 426-432 681

Xing H, Sun J, Yao Q, Guo W Y and Chen R 2008 Appl. Phys. Lett. 92151905

Yang Y, Li G P, Cheng G M, Wang H, Zhang M, Xu F and Yang K 2008 Scr. Mater. 589

Zhao J and Adams B L 1988 Acta Crystallogr. A44 326 